\title{
El resurgimiento de la religión, ¿un reto para la autocomprensión de la modernidad?*
}

\author{
JÜRGEN HABERMAS \\ Profesor Emérito \\ Universidad de Fráncfort
}

\begin{abstract}
Resumen: El trabajo inicia con la revisión de la tesis de la secularización, que ligaba modernización y secularización a la luz de la reciente expansión global de las religiones. Se pregunta si esto último requiere una reconfiguración del marco conceptual de la teoría de la modernización. Mientras que la secularización ha tenido lugar efectivamente en la expansión de sistemas funcionales más allá de las fronteras nacionales, la religión no se ha vuelto irrelevante como "comunidad de interpretación" en numerosos asuntos sociales y morales. La tesis de la secularización no está ya vinculada al concepto de evolución social, y esto implica una perspectiva distinta respecto de las fuentes de la filosofía moderna: el pensamiento posmetafísico se ha apropiado críticamente de contenidos de la tradición judeocristiana que no son menos importantes que los de la metafísica griega. No obstante, el pluralismo persistente de visiones del mundo es también un estímulo para el desarrollo del derecho internacional y de principios compartidos de justicia para una sociedad mundial multicultural.
\end{abstract}

Palabras clave: teorías de la secularización, religiones del mundo, modernidad multicultural, justicia internacional

\begin{abstract}
The paper begins with a revision of the secularization thesis that linked modernization with secularization in the light of the recent worldwide expansion of religions. It asks whether and how the later phenomena requires a reconfiguration of the conceptual framework of modernization theory. While secularization has taken place effectively in the expansion of functional systems across state boundaries, religion has not become irrelevant as a "community of interpretation" on many social and moral issues. A new understanding of the secularization thesis is no longer linked to the concept of social evolution, and this implies a changed perspective on the sources of modern philosophy: post-metaphysical thought has critically appropriated contents from the Judeo-Christian tradition that are no less important than those of Greek metaphysics. But the persisting pluralism of worldviews is also a stimulus for the development of international law and shared secular principles of justice for a multicultural world society.

Key words: secularization theory, world-religions, multicultural modernity, international justice

* Conferencia magistral leída en el XIV Congreso Internacional de Filosofía, Mazatlán, México, 9 de noviembre de 2007. Agradecemos la gentileza del Profesor Habermas de autorizar la publicación de este texto inédito, que forma parte de un
\end{abstract} libro en progreso.

Diánoia, volumen LIII, número 60 (mayo 2008): pp. 3-20. 
JÜRGEN HABERMAS

I

Permítanme comenzar con la pregunta que afecta en primera instancia a Europa, pero que podría ser pertinente para otras sociedades: ¿qué significa el resurgimiento de la religión para una sociedad ampliamente secularizada?

1. Desde los tiempos de Max Weber y Emile Durkheim, la tesis que postula una cercana interrelación entre la modernización de la sociedad y la secularización de la conciencia no había suscitado mayores controversias. Dicha tesis descansa en tres consideraciones:

Primero, el progreso de la ciencia y la tecnología promueve un entendimiento antropocéntrico del mundo "desencantado" puesto que la totalidad de estados de cosas y eventos empíricos puede ser explicada causalmente; dicho humanismo, por su parte, no puede reconciliarse fácilmente con visiones del mundo teocéntricas y cosmocéntricas. Segundo, como consecuencia de la diferenciación funcional de los subsistemas sociales, las iglesias y otras organizaciones religiosas perdieron el control sobre la ley, la política, el bienestar público, la cultura, la educación y la ciencia, y quedaron restringidas a su función propiamente dicha de administrar los medios de salvación. El ejercicio de la religión se convirtió en asunto privado y en general perdió influencia y relevancia pública. Finalmente, el paso de las sociedades agrarias a las sociedades postindustriales condujo a niveles más altos de bienestar y seguridad social, y con la disminución del riesgo y la creciente seguridad existencial se atenuó también la necesidad, profundamente arraigada, de una práctica que prometía manejar las contingencias incontrolables acudiendo a la fe en un poder "superior" o cósmico. De hecho, se debilitaron los vínculos religiosos de los ciudadanos de las sociedades más ricas de Europa, Canadá, Australia o Nueva Zelanda, primero de manera gradual, y desde el final de la segunda guerra mundial de manera más dramática.

Dentro de la comunidad de expertos en sociología, sin embargo, la tesis de la secularización se ha vuelto un tópico controvertido en las dos décadas pasadas (Hadden 1987). Esta tesis es vulnerable a la sospecha de que solamente transformó en una gran narrativa los lugares comunes de la intelligentsia occidental entre 1870 y 1910 (Martin 2005, introd.). Recientemente, en la bien fundada ola de críticas a la perspectiva eurocéntrica estrecha, se habla incluso del "fin de la teoría de la secularización". ${ }^{1}$ Estados Unidos, con la vitalidad no disminuida de sus

${ }^{1}$ Hans Joas, "Gesellschaft, Staat und Religion", Joas 2007, pp. 9-43.

Diánoia, vol. LIII, no. 60 (mayo 2008). 
comunidades religiosas y una proporción estable de ciudadanos comprometidos y activos religiosamente, se mantiene no obstante como la fuerza impulsora de la modernización, por lo que ha sido considerado como la gran excepción a la tendencia secularizadora. Desde la perspectiva globalmente extendida hacia otras culturas y religiones del mundo parece ahora, en cambio, ejemplificar el caso normal.

Para esta postura revisionista el desarrollo europeo, cuyo racionalismo occidental alguna vez se presupuso como modelo para el resto del mundo, representa ahora la ruta anómala (Sonderweg). ${ }^{2}$ Pero, sobre todo, tres fenómenos traslapados convergen para dar la impresión de un "resurgimiento global de la religión": la expansión misionera, la radicalización fundamentalista y la instrumentalización política del potencial para la violencia de las tres grandes religiones del mundo:

- Respecto del primero, la expansión misionera, puede detectarse un primer signo de vitalidad en el avance generalizado de los grupos ortodoxos, o en cualquier caso conservadores, de las iglesias y las denominaciones religiosas establecidas. Esta afirmación es válida tanto para el hinduismo y el budismo como para las tres religiones monoteístas. Lo más sorprendente de todo es la expansión regional de estas religiones establecidas en África y en los países del este y sudeste de Asia. El éxito misionero parece también depender de la flexibilidad de sus formas de organización. La Iglesia católica romana, por su carácter transnacional y multicultural, se adapta mejor a la tendencia globalizadora que las iglesias protestantes nacionalmente organizadas, que son las principales perdedoras. Las más dinámicas de todas son las redes descentralizadas del Islam (sobre todo en África, al sur del Sahara) y las de los evangélicos (especialmente en América Latina). Lo que distingue a estos grupos es una forma extática de religiosidad inspirada en los líderes carismáticos.

- En lo que se refiere al segundo fenómeno, los movimientos religiosos que están creciendo mas rápidamente, como los pentecostales y los musulmanes radicales, pueden ser descritos como fundamentalistas. Su forma de culto combina el espiritualismo y el adventismo con concepciones morales rígidas y una adhesión literal a las Sagradas Escrituras. De modo contrastante, los "nuevos movimientos religiosos" que han proliferado desde los años setenta manifiestan un sincretismo "californiano" y comparten con los

${ }^{2}$ Peter L. Berger, "The Desecularization of the World: A Global Overview", en Berger 2005, pp. 1-18. 
evangélicos una forma desinstitucionalizada de observación religiosa. En Japón, por ejemplo, han surgido aproximadamente 400 de estas sectas que combinan elementos del budismo y la religiosidad popular con doctrinas pseudo-científicas y esotéricas. En la República Popular China, la represión política de la secta Falun Gong ha llamado la atención sobre el gran número de "nuevas religiones" cuyos seguidores se cree que alcanzan los 80 millones. $^{3}$

- En tercer lugar, respecto de la radicalización política, el régimen de los ayatolas en Irán y el terrorismo islámico son solamente los ejemplos más espectaculares del desencadenamiento del potencial para la violencia que subyace a la religión. Con frecuencia, conflictos latentes de origen profano se encienden cuando se codifican en términos religiosos. Esto es cierto para la "desecularización" del conflicto del Oriente Medio, las políticas del nacionalismo hindú y el conflicto soterrado entre la India y Pakistán; ${ }^{4}$ así como para la movilización de la derecha religiosa en Estados Unidos antes y durante la invasión de Irak.

2. No puedo discutir con detalle la controversia entre los sociólogos sobre el supuesto Sonderweg (ruta anormal) de las sociedades europeas dentro de una sociedad mundial movilizada religiosamente. Mi impresión es que los datos recabados globalmente apoyan de modo sorprendentemente robusto a los defensores de la tesis de la secularización (Norris e Inglehart 2004). Mientras que las sociedades desarrolladas son cada vez más seculares, la sociedad mundial es cada vez más religiosa; esto último, como resultado de las altas tasas de natalidad en los países más pobres o en desarrollo. Aunque, por supuesto, la expansión dinámica de la religión no puede ser explicada solamente en términos de tendencias demográficas. Un examen más cuidadoso de los campos afectados tiende a confirmar la hipótesis de que existe una conexión entre la inseguridad existencial y la necesidad religiosa. Por ejemplo, diversos grupos vulnerables en Latinoamérica, Asia o África son más receptivos a los mensajes de los líderes carismáticos de las megaiglesias evangélicas; ${ }^{5}$ de modo que la radicalización fundamentalista y la ins-

${ }^{3}$ J. Gentz, "Die religiöse Lage in Ostasien”, en Joas 2007, pp. 358-75.

${ }^{4}$ Cfr. Las contribuciones de H.G. Kippenberg y H. Von Stietencron, en Joas 2007, pp. 456-507, y 194-223.

${ }^{5}$ D. Martin, "Evangelical Expansion in Global Society", en Martin 2005, pp. 2646.

Diánoia, vol. LIII, no. 60 (mayo 2008). 
trumentalización política de las comunidades religiosas también puede ser explicada en términos consistentes con la tesis de la secularización. ${ }^{6}$

Ciertamente, el desarrollo de la conciencia religiosa en Estados Unidos no encaja con el patrón de secularización progresiva. Norris e Inglehart ofrecen dos explicaciones de la vitalidad religiosa de la sociedad norteamericana: en primer lugar, una explicación demográfica en términos de tasas comparativamente altas de inmigrantes que provienen de sociedades predominantemente tradicionales con orientaciones religiosas y altas tasas de natalidad. En segundo lugar, una explicación estructural que señala la debilidad de los sistemas de seguridad social en Estados Unidos, inadecuados para proteger a los sectores vulnerables y susceptibles de la población de los riesgos de un capitalismo salvaje, a diferencia de la situación todavía, en gran medida, prevaleciente en Europa.

En mi opinión, la debilidad de la teoría de la secularización se debe a inferencias apresuradas que revelan un uso inapropiado de los conceptos de "secularización" y "modernización". Es cierto que, en el transcurso de la diferenciación de los sistemas sociales funcionales, las iglesias y las comunidades religiosas se confinaron cada vez más a su tarea central de cuidado pastoral y tuvieron que abandonar atribuciones en otros campos sociales. Al mismo tiempo, la práctica de la fe se refugió en espacios recluidos o dominios personales. Existe una correlación entre la especificación funcional del sistema religioso y la individualización de las prácticas religiosas. Sin embargo, como José Casanova anota correctamente, la pérdida de funciones y la tendencia hacia la privatización no implican necesariamente una pérdida de relevancia e influencia de la religión, ya sea en la arena política y la cultura de una sociedad, o en la conducción de la vida personal (Casanova 1994).

Independientemente de su peso en términos numéricos, las comunidades religiosas pueden obviamente reclamar un "sitio" en la vida de las sociedades modernas. Pueden influir en la opinión pública y en la formación de la voluntad por medio de contribuciones relevantes (que pueden o no resultar convincentes) dentro de los debates en curso. Nuestras sociedades pluralistas presentan un marco sensible de respuesta a dichas intervenciones porque están cada vez más divididas y atravesadas por conflictos de valores que requieren regulación política. Las comunidades religiosas pueden ser reconocidas como "comunidades de interpretación" en la arena política de las sociedades pre-

\footnotetext{
${ }^{6}$ Risenbrodt 2000, y Bielefeldt y Heitmeyer 1998.
} 
dominantemente seculares. ${ }^{7}$ Por ejemplo, en controversias acerca de la legalización del aborto o la eutanasia, o sobre problemas bioéticos de la medicina reproductiva, o sobre cuestiones como la protección de los animales y el cambio ambiental, en estos tópicos y temas similares, los argumentos son tan controvertidos que de ninguna manera puede considerarse de antemano que alguna de las partes posea las intuiciones morales más convincentes.

En nuestros días, la conciencia pública en Europa puede ser descrita en términos de una "sociedad post-secular" que por el momento debe "adaptarse a la existencia duradera de comunidades religiosas en un entorno crecientemente secularizado". ${ }^{8}$ La conciencia de vivir en una sociedad secular no está ya ligada a la certeza de que el avance de la modernización de la sociedad y la cultura sólo pueden ocurrir si se sacrifica la influencia pública y la relevancia personal de la religión.

En este sentido, propongo una lectura revisada de la tesis de la secularización, no como una cuestión sustantiva, sino referida al futuro papel de la religión. El cambio de énfasis nos recuerda que la tesis de la secularización estaba originalmente ligada al concepto más ambicioso de evolución social. ${ }^{9}$ Cómo estimar el futuro de la religión dependerá también de cómo se conciban las potencialidades de la condición moderna en general.

II

Permítanme, por lo tanto, pasar a la pregunta más general: ¿cómo debemos concebir la sociedad mundial multicultural emergente?

Se trata de preguntarnos si el surgimiento de múltiples modernidades simplemente altera el fenómeno de superficie o si es un nuevo fenómeno que requiere una reconfiguración culturalista del marco conceptual de la teoría de la modernización. Tres enfoques compiten en este campo: primero compararé la concepción funcionalista de una "sociedad mundial" con la visión opuesta de un culturalismo radical, para después examinar una tercera concepción que intenta ligar las dos perspectivas.

Si seguimos a Niklas Luhmann en su concepción de la sociedad mundial como resultado de una dinámica evolutiva que impulsa la diferenciación funcional más allá de las fronteras de las sociedades naciona-

${ }^{7}$ Francis Schüssler Fiorenza, "The Church as a Community of Interpretation", en Browning y Schüssler Fiorenza 1992, pp. 66-91.

${ }^{8}$ Habermas, "Faith and Knowledge", en Habermas 2003, pp. 101-115.

${ }^{9}$ Inglehart y Welzel 2005, parte 1 . 
les, la imagen de sistemas funcionales que se expanden a través de las fronteras nacionales nos llama la atención. ${ }^{10}$ Con la creciente desespacialización de la comunicación en las redes globales y siguiendo especialmente la tendencia acelerada de la circulación global irrestricta de personas, bienes, servicios y capital, otros subsistemas como la ciencia y la tecnología, la música y la cultura de masas, los deportes y el crimen organizado, el derecho, la medicina, la educación, etc., atraviesan también las fronteras entre los estados y las culturas (Stichweh 2000). En la fase más reciente de globalización económica no hay manera de escapar del alcance del capitalismo. Por el contrario, la misma infraestructura se está transformando en todas las regiones del mundo: los mismos patrones de urbanización y redes de transporte, organizaciones administrativas semejantes, los mismos sistemas de salud y educación, o de los medios de comunicación de masas, etcétera.

Oponiéndose a esta clase de teoría social, los enfoques culturalistas insisten en que esta fijación en la "civilización" en singular distrae la atención de las características únicas de las civilizaciones que son siempre plurales. ${ }^{11}$ Contrastando el concepto sociológico de "sociedades" como estados territorialmente circunscritos capaces de acción colectiva, entendemos a las "civilizaciones" como formaciones históricas geográficamente extendidas y aglutinadas por tradiciones fuertes que generalmente son religiones de alcance mundial. Se estructuran de forma difusa en términos de centro y periferia y pueden incorporar diferentes sociedades tanto sincrónicamente como a lo largo del tiempo. En la interpretación de Arnold Toynbee (o aun en la de Oswald Spengler), las esferas culturales o las civilizaciones mismas son reificadas como macrosujetos que se demarcan de las totalidades y "chocan" como actores colectivos cuando dejan de coexistir indiferentes los unos de los otros. A diferencia de la estrategia generalizadora de la teoría social clásica, esta concepción esencialista de "culturas" autocontenidas — por ejemplo, en Samuel Huntington (Huntington 1996) — propicia la idea particularista de una relación existencial entre las culturas descrita en términos de amigos y enemigos.

Ninguna de estas dos interpretaciones puede hacer justicia al importante fenómeno de la modernidad contemporánea; esto es, a la variedad de formas que la "modernidad social" adopta en otras regiones del mundo. El culturalismo radical es ciego frente a la expansión global de sistemas funcionales que siguen la misma lógica en todas partes: el

${ }^{10}$ Niklas Luhmann, "Die Weltgesellschaft”, en Luhmann 1975, pp. 51-71.

${ }^{11}$ Véase para lo que sigue: Arnason 2003, capítulo 1: "The Rediscovery of Civilizations". 
mercado induce, por supuesto, a todos los hombres de negocios, o a los inversionistas y consumidores, a maximizar ganancias y compensar pérdidas, ya sea en África, en Asia o en América Latina. La teoría de sistemas, por su parte, sólo registra los efectos niveladores de las tendencias evolucionistas generales. Sin embargo, otras civilizaciones de hecho toman las presiones de occidente para modernizar sus sociedades como retos a los que responden acudiendo a recursos culturales propios. En la actualidad, la misma tensión dialéctica entre tradición y modernidad que caracterizó al desarrollo de la modernidad occidental opera también en otros complejos de civilización. Esto es particularmente notable en las culturas del este de Asia. Allí las tradiciones autóctonas no solamente configuran el estilo de vida de la comunicación cotidiana y la fisonomía distintiva del mundo de la vida, sino que afectan también la institucionalización de la burocracia estatal y los mercados, el diseño arquitectónico y la planeación de las megaurbes, el ethos educativo, el peso relativo que se asigna al trabajo, el consumo, el ocio, los deportes, la seguridad, etcétera.

Esta clase de observaciones llevaron a S.N. Eisenstadt a proponer una tercera concepción de la modernidad. ${ }^{12}$ Este autor interpreta la idea de una sociedad multicultural mundial como una nueva formación cultural que se ha desacoplado por igual de todas las civilizaciones tradicionales, incluyendo a occidente, a través de una dinámica global de modernización. La perspectiva generalizadora de la teoría social se combina de este modo con la perspectiva comparativa del estudio de las civilizaciones(Arnason 2003). A partir de una infraestructura social globalizada (cuya principal característica es su orientación obstinada al control científico-tecnológico de la naturaleza, el ejercicio burocrático del poder y la producción capitalista de riquezas), la modernidad hoy en día constituye algo así como la arena común donde las diferentes civilizaciones se encuentran unas con otras, al mismo tiempo que modifican esta infraestructura en formas más o menos culturalmente especificas y confrontan versiones rivales de la autocomprensión de la modernidad.

"La modernidad" surgió en occidente como un concepto cultural $^{13}$ que hace referencia a la base social de condiciones de vida revolucionadas que se experimentan como algo radicalmente nuevo, y al mismo tiempo codetermina dichas condiciones de vida a través de su poder de definición (Habermas 1990). Arnason concibe de manera parecida la

${ }^{12}$ Arnason, Eisenstadt, y Wittrock 2005.

${ }^{13}$ H.R. Jauss, "Ursprung und Bedeutung der Fortschrittsidee in der 'Querelle des Anciens et des Modernes'”, en H. Kuhn y F. Wiedmann 1964, pp. 51-72. 
modernidad globalizada contemporánea: considera que surge de raíces culturales múltiples, como escenario de la lucha por las definiciones de una base social compartida. A su vez, esta lucha afecta a esa misma base y da cuenta de la fragmentación cultural de la sociedad mundial. ${ }^{14}$

No obstante, la imagen de un mundo culturalmente dividido y, por lo tanto, no completamente integrado, oscurece el hecho perturbador de que dichos conflictos de interpretación a nivel de identidades culturales con frecuencia encubren la escandalosa desigualdad en la distribución del poder y la riqueza, así como el darwinismo social impulsado por intereses de la política mundial actual. Quisiera hacer notar, sin embargo, que existe otra tendencia prometedora aunque débil: la de una red legal cada vez más densa para la integración transnacional de una sociedad mundial, que si bien está llena de conflictos, dirige nuestra atención a una dimensión adicional, hasta al momento desatendida, del concepto de sociedad mundial. Dicha dimensión, la de una integración por medio del derecho internacional, añade un nuevo elemento al concepto de una sociedad mundial dividida culturalmente y destaca un aspecto diferente de la secularización.

Los presupuestos cognoscitivos que deben ser satisfechos para que tenga éxito el discurso intercultural basado en principios de justicia política para la sociedad multicultural mundial son de particular interés en este contexto. Todos los involucrados, independientemente de sus trasfondos culturales, tienen que considerar simultáneamente los temas controvertidos: desde su propia perspectiva y desde la de los otros participantes. Además, deben aprender a limitarse exclusivamente a los argumentos que pudieran, en principio, convencer a cualquiera independientemente de los compromisos metafísicos o religiosos subyacentes. Aparte de los aspectos sustantivos de un acuerdo eventual, estos procedimientos podrían generar un acuerdo mutuo ideológicamente neutralizado, y en este sentido procurar un nivel secular de entendimiento mutuo. Visto de esta manera, el debate sobre la secularización toma una nueva dirección.

\section{III}

En nuestros días, el debate se plantea como una pregunta acerca de las posibles convergencias, a nivel secular, del discurso intercultural sobre principios de justicia internacional.

${ }^{14}$ Arnason 2003, p. 325.

Diánoia, vol. LIII, no. 60 (mayo 2008). 
La pregunta ya no consiste en investigar si bajo las condiciones sociales modernas la religión está destinada a desaparecer o a perder cualquier relevancia pública. Más bien tenemos que enfrentar ahora la presencia vital de religiones en expansión, mientras, que al mismo tiempo, sólo quedan en el mundo sociedades más o menos modernas. Estas sociedades, por su parte, están constantemente enfrascadas en controversias sobre el significado del proyecto de la modernidad y tienen que enfrentar algunos hechos fundamentales, tales como:

- Las presiones racionalizadoras e individualizadoras de la sociedad de mercado y estados administrativos de todo tipo.

- Los discursos legales, económicos y científicos que producen formas falibles de conocimiento mundano.

- El pluralismo de visiones del mundo y formas de vida que representan, en cada caso, alternativas a la fe y el ethos de cada uno.

Por lo tanto, la cuestión de la correlación entre modernización y secularización se presenta de manera distinta: ¿pueden las culturas, al enfrentar estos hechos, resistir la atracción de un distanciamiento autorreflexivo? ¿Podrán las culturas tradicionales en transición hacia una modernidad multicultural transformar su orientación religiosa original y proporcionar los recursos cognoscitivos para desacoplar creencias débiles generalmente aceptables - y en este sentido seculares- de descripciones densas y argumentos que dependen de religiones particulares? Si esto último fuera el caso, ¿será capaz la sociedad multicultural mundial de evolucionar hacia una especificación funcional de tradiciones religiosas y comunidades, que aunque conserven su influencia pública, eviten al mismo tiempo prejuzgar la legitimación secular autosustentada del derecho y la política (John Rawls)?

Sólo bajo estas condiciones, la tendencia hacia una constitucionalización liberal del derecho internacional ${ }^{15}$ podría tener alguna posibilidad de éxito. ${ }^{16} \mathrm{Si}$, por lo contrario, la llamada "escuela realista" estuviera en lo correcto al suponer que algo así como "la justicia entre naciones" es imposible debido a la clausura semántica de visiones del mundo inconmensurables, lo más que podría esperarse sería una concepción del

${ }^{15}$ Véase: Leibfried y Zürn 2005, así como el estudio subsecuente: A. Hurrelman, S. Leibfried, K. Martens y P. Mayer (comps.), Transforming the Golden-Age Nation State, Palgrave Macmillan, 2008.

${ }^{16}$ Para algunos esbozos sobre una sociedad mundial políticamente constituida, véase también mi respuesta en: Niesen y Herbort 2007, pp. 406-59, en especial: pp. 422 y ss.

Diánoia, vol. LIII, no. 60 (mayo 2008). 
orden mundial à la Carl Schmitt, que imagina un mundo dividido en "hemisferios" imperiales pacificados por la prohibición de intervención de "poderes externos". ${ }^{17}$

A estas alturas del argumento, no debemos dejarnos atrapar por el prejuicio que supone que corresponde principalmente a las religiones emprender el discurso intercultural y aprender de éste. Supongamos, contrafácticamente, que todas las grandes comunidades religiosas se hubieran beneficiado ya de la reflexividad interconstruida en las formas de vida modernas y hubieran conseguido asimismo un acuerdo intercultural sobre una constitución política para la sociedad multicultural mundial. Dicho proceso, indudablemente, habría tenido que enfrentar demoras, interrupciones y retrocesos. Sin embargo, a pesar de los desacuerdos persistentes sobre la autocomprensión correcta de la modernidad, podría haber conducido finalmente a la aceptación de reglas y procedimientos de lo que podríamos llamar un sistema constitucionalizado de derecho internacional. El proceso habría seleccionado un conjunto particular de argumentos; esto es, los argumentos conceptuales, empíricos, científicos, morales y legales que hubieran demostrado ser los más convincentes para todos, a la luz de la experiencia compartida de las condiciones modernas de vida, y a pesar de las visiones del mundo en conflicto. Podemos caracterizar como "razón secular" a la facultad de la que dependen estos argumentos.

No obstante, esta genealogía presenta una imagen incompleta, ya que, en nuestro experimento mental, hasta ahora sólo hemos considerado interlocutores cuyas diferentes mentalidades habrían sido formadas por el trasfondo religioso de tradiciones culturales. Otra clase de desacuerdo, que deber ser superado, es aquel que tiene lugar entre los ciudadanos religiosos y los ciudadanos seculares (o las elites), y éste atraviesa a la sociedad civil en todos los países. Estas últimas disputas se refieren a la manera en que debe ser entendida la razón secular misma.

Los partidarios de tradiciones fuertes y doctrinas comprensivas estarían de acuerdo - en el modelo del consenso traslapado de John Rawls- en los principios básicos para construir un orden político justo, cada uno desde el horizonte de su propia visión del mundo. Para los creyentes, los argumentos públicos - y en este sentido seculares- que apoyan los principios compartidos de justicia política derivan su fuerza persuasiva del hecho de estar ligados a sus respectivas visiones del mundo, y estos encajan como piezas modulares en visiones del mundo

${ }^{17}$ Carl Schmitt 1991 [1941]. También: Schmitt 1987 [1950]. 
razonables. ${ }^{18}$ En estas condiciones, contarían como públicos sólo los argumentos que no pusieran en duda las pretensiones de verdad de la religión, o de la metafísica como tal.

Por el contrario, los individuos cuya comprensión del mundo y de ellos mismos proviene exclusivamente de fuentes seculares poseen una visión menos restringida de la razón secular; para ellos, la "razón" no es lo que resulta como el común denominador más bajo entre las visiones del mundo en conflicto, sino que constituye una autoridad por derecho propio. ${ }^{19}$ Para una perspectiva religiosa, el conjunto de argumentos seculares está restringido de antemano, de tal manera que no pueden surgir disonancias cognoscitivas para los creyentes; en cambio, para el punto de vista secular, la razón es la que determina por derecho propio lo que cuenta como un argumento válido o inválido en cada caso.

Esto no necesariamente nos lleva a una valoración despectiva de las intenciones éticas y el contenido potencial de verdad de las doctrinas religiosas y las visiones del mundo metafísicas; permite más bien un agnosticismo moderado. Pero una objeción laica fuerte de los "no creyentes" respecto de la doctrinas proféticas y las visiones del mundo metafísicas podría ciertamente intensificar - ya sea dentro de una cultura o a escala global- el conflicto entre los contendientes y podría convertirse en algo tan serio como los conflictos entre religiones hostiles. Cuando el secularismo excluye a los conciudadanos creyentes del círculo de los contemporáneos modernos y los trata como si fueran una especie en peligro de extinción, se corroe la sustancia misma de la membresía igualitaria debida a todos en el universo de personas racionales. Sin esta última concepción, la igualdad ciudadana de los miembros de una comunidad democrática queda a merced de los vaivenes de un mero modus vivendi. Me he referido a lo que esto significa para la estabilidad del estado constitucional en otro lugar. ${ }^{20}$ En el presente contexto de la secularización, lo que me interesa es la diferencia entre una autointerpretación de la razón secular y otra secularista.

Como complemento al concepto de sociedad multicultural mundial de Eisenstadt, he propuesto añadir un nivel cognoscitivo compartido que podría permitir al menos acuerdos débiles sobre lo que puede contar como "justicia entre las naciones". No obstante, el éxito de esta

${ }^{18}$ Rawls 1993, p. 12 y ss.

${ }^{19}$ J. Habermas, “'Reasonable' vs. 'True', or the Morality of Worldviews”, en Habermas 1998, pp. 75-101.

${ }^{20}$ J. Habermas, "Religion in the Public Sphere: Cognitive Presuppositions for the 'Public Use of Reason' by Religious and Secular Citizens", en Habermas 2006, capítulo 5.

Diánoia, vol. LIII, no. 60 (mayo 2008). 
integración no depende solamente de que todas las comunidades religiosas se abran a la asimilación cognoscitiva de los hechos básicos de la modernidad; en las sociedades postseculares existe además un factor adicional; esto es, se requiere un proceso de aprendizaje complementario por parte de las mentalidades seculares, que cuestiona las formas estrechas de entender lo que significa la razón secular.

\section{IV}

La interpretación de la razón secular.

1. Generalmente asociamos el carácter secular de la razón con el sentido negativo de abstenerse de premisas que apelan a la revelación divina. Pero la autonomía de la razón no sólo depende de la distinción entre lumen naturale y sacra doctrina, sino que significa también que la fe no puede ya agregar nada relevante al conocimiento propiamente dicho. Dado que el pensamiento "secular" adquirió un significado positivo por primera vez en el transcurso de la reflexión acerca de cuestiones tales como las siguientes:

- El nuevo tipo de conocimiento de la naturaleza que surgió desde el siglo XVII.

- La nueva experiencia que lo acompaña y que consiste en la pérdida de inocencia inducida por los avances en el conocimiento de las ciencias naturales, sociales y humanas.

El efecto ilustrado de toda la ciencia moderna contiene en sí mismo el germen de la crítica de la religión. Mientras que las críticas basadas en las ciencias naturales afectan la doctrina bíblica de la creación, la crítica histórica sobre las fuentes ataca de lleno el corazón de la herencia bíblica. Comparados con estos ataques, los efectos de la sociología o la antropología de la religión son relativamente indirectos, ya que promueven un entendimiento funcionalista de la razón.

Pero desde una perspectiva posmetafísica, la disputa entre diferentes religiones o enseñanzas cosmológicas sobre quién tiene la razón ya no acepta una solución racional. El pluralismo persistente de la visiones del mundo se transforma, en cambio, en estímulo para el desarrollo de una moralidad autónoma y un derecho profano de respeto igualitario para todos; ambos fundados solamente en la razón. La moralidad racional y el derecho se abstienen de privilegiar cualquiera de las formas vinculantes de concepciones de la vida buena. Por lo tanto, sólo pueden "contar" aquellos enunciados que logren acuerdos independientes de los contextos implícitos de las religiones o las cosmologías. 
La razón constructiva, que genera todos los acuerdos normativos a partir de ella misma, encuentra en Kant el representante de una visión de la humanidad que conecta una cultura ilustrada basada en el conocimiento con la organización justa de la sociedad, asegurando la paz e igual libertad para todos. En la forma de un derecho racional, este espíritu humanista inspiró también al estado secular que garantiza la libre práctica de la religión. Al mismo tiempo, la razón secular mantiene la religión a distancia. En la medida en que la razón secular está dispuesta a relacionarse con la religión como una formación espiritual concurrente, no la trata como su igual. La filosofía reclama para sí el privilegio de determinar lo que es o no racional en las tradiciones religiosas. Una religión que se incorpora de este modo a la filosofía deja de ser para los creyentes, por supuesto, una religión.

2. Finalmente, la confianza en la autocomprensión humanista de la modernidad ha sido cuestionada históricamente no sólo por el colonialismo imperialista del siglo XIX y las catástrofes del siglo Xx; desde que Hegel descubrió la herencia religiosa en el corazón mismo de la filosofía, la autocomprensión filosófica de la Ilustración ha cambiado también. El derecho racional moderno surgió indudablemente de la crítica al derecho natural cristiano; pero una mirada cuidadosa a la escolástica española muestra que la tradición de los derechos humanos pudo haberse nutrido del universalismo igualitario de la creación del "hombre" a imagen y semejanza de dios. ${ }^{21} \mathrm{El}$ concepto moderno de la persona individual y de la fuerza individualizadora de una historia de vida, extrae de la noción bíblica de una vida conducida a los ojos de dios las connotaciones de ser algo único e irremplazable, así como las nociones de subjetividad e interioridad. ${ }^{22}$ La moralidad secular de respeto igualitario para todos conserva el carácter categórico de obligaciones incondicionalmente válidas porque el "punto de vista moral" preserva residuos de la trascendencia inmanente del punto de vista divino del juicio final.

Estos ejemplos ilustran una herencia que fue adoptada por el pensamiento posmetafísico derivado de la simbiosis entre el pensamiento cristiano y la metafísica griega lograda ya durante la Edad Media. Pero, desde entonces, la filosofía moderna ha recibido también otros estímulos directos de las tradiciones escatológicas y apocalípticas al enfrentar el reto de ofrecer un diagnóstico de lo que es nuevo en la "nueva era".

${ }^{21}$ Böckenförde 2002, pp. 212-370, y Stein 2007.

22 J. Habermas, "Individuation through Socialization: On George Herbert Mead's Theory of Subjectivity”, en Habermas 1992, pp. 149-204. 
El discurso filosófico de la modernidad, que comenzó con el diseño de utopías sociales y continuó en la filosofía de la historia y la teoría crítica de la sociedad, se nutrió asimismo de ideas e imágenes bíblicas. El sentido de una crisis inminente otorga a esta crítica la dimensión nueva de la expectativa fatalista del Segundo Advenimiento. El concepto de emancipación infunde a la concepción igualitaria de la libertad el dinamismo antiautoritario de la historia de la salvación. Los llamados a una fraternidad incluyente y a la solidaridad se nutren del recuerdo de la vida comunitaria de las religiones del mundo que se extienden a través de fronteras espaciales y temporales.

La actitud polémica de la Ilustración hacia los poderes terrenales de la religión tiende a oscurecer el hecho de que el pensamiento posmetafísico se ha apropiado también, críticamente, de contenidos de la tradición judeocristiana que no son menos importantes que los de la herencia de la metafísica griega. Este bagaje oculto no afectó el carácter secular de este pensamiento, puesto que, desde el giro antropocéntrico, éste se consideraba incompatible con cualquier orientación teocéntrica. Al mismo tiempo, por otra parte, la filosofía práctica que adoptó el ateísmo metodológico como su base, extrajo contenidos cognoscitivos de la verdad revelada y los "tradujo" a su propio discurso; para el discurso filosófico sólo cuentan las razones "públicas"; esto es, aquellas capaces de lograr convicciones mas allá de una comunidad religiosa particular.

El hecho de que el pensamiento posmetafísico haya sido inspirado por contenidos religiosos en modo alguno borra la frontera entre la "fe" y el "conocimiento". Aún si los contenidos semánticos pueden cruzar esta frontera bajo apariencias diferentes, los distintos modos de "creer" y "aceptar como verdadero" permanecen intocados. Sus enunciados respectivos apelan a bases de justificación diferentes y se vinculan con pretensiones de validez que difieren en clase y extensión.

Conclusiones: Permítanme concluir con la pregunta acerca de aquello que la razón secular podría aprender al adquirir conciencia de su conexión genealógica con la herencia judeocristiana. Hegel, en la encrucijada de su dialéctica, aún más que Kant, rescató contenidos de la doctrina cristiana de su caparazón dogmático. Pero, al igual que Kant, interpretó las ideas religiosas como un "pensamiento representativo" y dejó a la filosofía decidir qué es falso o verdadero en la religión. En su "concepción" de las tradiciones religiosas, supuso que la religión es esencial- 
mente un fenómeno del pasado del que la filosofía no tiene ya nada que aprender. Sin embargo, ¿́podemos estar seguros de haber completado la tarea de apropiación discursiva de los contenidos religiosos? Repetidamente, de Kierkegaard a Benjamin, o con Levinas y Derrida, han surgido "escritores religiosos" que independientemente de sus visiones personales han enriquecido el pensamiento secular con la traducción de contenidos teológicos.

¿Puede el pensamiento posmetafísico que ha renunciado al concepto fuerte de Teoría de Hegel (teoría con T mayúscula) excluir la posibilidad de que las tradiciones religiosas involucren potenciales semánticos que al liberar sus contenidos de verdad profanos sean todavía capaces de inspirar a la sociedad civil cuando ésta tiene que enfrentar retos de conflictos de valores? El pensamiento posmetafísico debe adoptar una actitud al mismo tiempo agnóstica y receptiva hacia la religión sin comprometer su autocomprensión secular. Para una mentalidad secular, la fe retiene una cualidad opaca, que no puede ni negar ni simplemente aceptar. La razón secular debe insistir en la diferencia entre las certezas de la fe y las pretensiones de validez públicamente criticables, pero abstenerse de evaluar la racionalidad o irracionalidad de la religión como tal. ${ }^{23}$

Pienso que la autocomprensión posmetafísica de la razón puede no solamente servir de base a procesos de aprendizaje mutuos, sino que también puede ayudar a salvar la distancia entre el pathos religioso y el secular comprometiéndose con un discurso intercultural acerca de principios comunes de justicia política para la sociedad mundial multicultural.

[Traducción del inglés de María Herrera y Eduardo Mendieta]

\section{BIBLIOGRAFÍA}

Arnason, J.P., 2003, Civilizations in Dispute, Brill, Londres/Boston.

Arnason, J.P., S.N. Eisenstadt y B. Wittrock (comps.), 2005, Axial Civilizations and the World History, Brill, Londres/Boston.

Berger, Peter (comp.), 2005, The Desecularization of the World: A Global Overview, W.E. Eerdmans Pub. Co., Grand Rapids MI.

${ }^{23}$ Karl Jaspers, por ejemplo, en su diálogo con Rudolf Bultmann, partió de premisas semejantes. Sin embargo, no comparte su relativización de la diferencia entre las ciencias y una forma de pensamiento posmetafísico que bajo el disfraz de una "fe filosófica" compite con la religión en igualdad de circunstancias. Véase Jaspers 1967, y Habermas, "The Clash of Beliefs", en Habermas 2001, pp. 30-45.

Diánoia, vol. LIII, no. 60 (mayo 2008). 
Bielefeldt, H. y Heitmeyer, W. (comps.), 1998, Politisierte Religionen, Suhrkamp, Fráncfort.

Böckenförde, Ernst-Wolfgang, 2002, Geschichte der Rechts-und Sozialphilosphie, Mohr-Siebeck, Tubinga.

Browning, D. y F. Schüssler Fiorenza (comps.), 1992, Habermas. Modernity, and Public Theology, Crossroads, Nueva York.

Casanova, J., 1994, Public Religions in the Modern World, The University of Chicago Press, Chicago.

Habermas, J., 2006, Between Naturalism and Religion, Polity Press, Cambridge.

- 2003, The Future of Human Nature, Polity Press, Cambridge.

_ 2001 , The Liberating Power of Symbols, Polity Press, Cambridge.

— 1998, The Inclusion of the Other: Studies in Political Theory, The MIT Press, Cambridge, Mass.

— 1992, Postmetaphysical Thinking: Philosophical Essays, The MIT Press, Cambridge, Mass.

— 1990, The Philosophical Discourse of Modernity, The MIT Press, Cambridge, Mass.

Hadden, J., 1987, “Towards Desacralizing Secularization Theory”, Social Force, vol. 65, pp. 587-611.

Huntington, S.P., 1996, The Clash of Civilizations and the Remaking of the World Order, Simon and Schuster, Nueva York.

Inglehart, R. y C. Welzel, (comps.), 2005, Modernization, Cultural Change, and Democracy, Cambridge University Press, Cambridge.

Jaspers, Karl, 1967, Philosophical Faith and Revelation, Harper and Row, Nueva York.

Joas, Hans (comp.), 2007, Säkularisierung und die Weltreligionen, Fischer, Fráncfort.

Kuhn, H. y F. Wiedmann, (comps.), 1964, Die Philosophie und die Frage nach dem Fortschritt, Anton Pustet, Munich.

Leibfried, S. y M. Zürn (comps.), 2005, Transformation of the State, Cambridge University Press, Cambridge.

Luhmann, Niklas, 1975, Soziologische Aufklärung 2, Westdeutscher Verlag, Opladen.

Martin, D., 2005, On Secularization, Ashgate, Burlington VT.

Niesen, P. y B. Herbort (comps.), 2007, Anarchie der kommunikativen Freiheit: Jürgen Habermas und die Theorie der Internationalen Politik, Suhrkamp, Fráncfort.

Norris, P. y R. Inglehart, 2004, Sacred and Secular: Religion and Politics Worldwide, Cambridge University Press, Cambridge.

Rawls, John, 1993, Political Liberalism, Columbia University Press, Nueva York.

Risenbrodt, M., 2000, Die Rückkehr der Religionen: Fundametalismus und der "Kampf der Kulturen", Beck, Munich.

Schmitt, Carl, 1991 [1941], Völkerrechtliche Grossraumordnung, Duncker and Humboldt, Berlín. 
Schmitt, Carl, 1987 [1950], Der Nomos auf Erde im Völkerrecht des Jus Publicum Europäum, Duncker und Humboldt, Berlín.

Stein, T., 2007, Himmlische Quellen und irdisches Recht, Campus, Fráncfort. Stichweh, R., Die Weltgesellschaft, Suhrkamp, Fráncfort.

Recibido el 21 de noviembre de 2007; aceptado el 31 de enero de 2008. 